\title{
MENSAGENS DA PRÁTICA PEDAGÓGICA EM TEXTOS DE MATERIAIS CURRICULARES EDUCATIVOS: UMA ANÁLISE A PARTIR DA DIMENSÃO INTERACIONAL
}

\author{
REINALDO FEIO LIMA ${ }^{1 ; 2 ; *}$ \\ ORCID: https://orcid.org/0000-0003-2038-7997 \\ ANDRÉIA MARIA PEREIRA DE OLIVEIRA ${ }^{1 ; 3 ; * *}$ \\ ORCID: https://orcid.org/0000-0002-8011-5179
}

\begin{abstract}
RESUMO: O objetivo deste artigo foi identificar e caracterizar as variações na mensagem que ocorrem na dimensão interacional, no que diz respeito à prática pedagógica escolar representada nos textos dos materiais curriculares educativos. Utilizamos o método qualitativo e a análise documental como procedimento. A teoria de Basil Bernstein foi o referencial teórico-metodológico, em especial, utilizamos o conceito de enquadramento no estudo. Os resultados obtidos indicaram que é perceptível a explicitação dos conteúdos de Geometria e Álgebra, no que se refere ao que ensinar e ao como ensinar, o uso sequenciado reprodutivo da tarefa matemática. Também com base nos resultados, identificamos que a mensagem em textos de materiais curriculares educativos caracteriza um forte controle do(a) professor(a) em relação às regras discursivas, seleção, sequenciamento, ritmagem e critérios de avaliação. Houve uma variação na intensidade do controle, quando professores e estudantes compartilharam a resolução da tarefa matemática. Além disso, o(a) professor(a) proporcionou uma comunicação aberta e um engajamento maior aos estudantes durante os processos de ensino e de aprendizagem.
\end{abstract}

Palavras-chave: Mensagens, texto, materiais curriculares educativos.

\section{MESSAGES FROM PEDAGOGICAL PRACTICE IN TEXTS OF EDUCATIVE CURRICULUM MATERIALS: AN ANALYSIS FROM THE INTERACTIONAL DIMENSION}

\begin{abstract}
The aim of this paper was to identify and characterize the variations in the message that occur in the interactional dimension, regarding the school pedagogical practice represented in the texts of the educative curriculum materials. We used the qualitative method and document analysis as a procedure. Basil Bernstein's theory was the theoretical-methodological framework, in particular, we used the concept of framing in the study. The results indicated that the geometry and algebra contents are noticeable, regarding what to teach and to how to teach, the reproductive sequential use of the mathematical task. Also based on the results, we identified that the message in texts of educative curriculum materials

\footnotetext{
${ }^{1}$ Universidade Federal da Bahia, Salvador, BA, Brasil

2 Universidade Federal do Sul e Sudeste do Pará, Santana do Araguaia, PA, Brasil.

${ }^{3}$ Universidade Estadual de Feira de Santana, Feira de Santana, BA, Brasil

*Doutor em Educação pela Universidade Federal da Bahia (UFBA). Professor Adjunto da Área de Educação Matemática da Universidade Federal do Sul e Sudeste do Pará (UNIFESSPA). E-mail: reinaldo.lima@unifesspa.edu.br.

**Doutora em Ensino, Filosofia e História das Ciências pela Universidade Federal da Bahia (UFBA), Universidade Estadual de Feira de Santana (UEFS). Professora Adjunta da Faculdade de Educação da Universidade Federal da Bahia, Professora Permanente do Programa de Pós-Graduação em Ensino, Filosofia e História das Ciências da UFBA/UEFS e do Programa de Pós-Graduação em Educação da UFBA. Salvador, BA, Brasil. E-mail: ampo@ufba.br
} 
characterizes a strong control of the teacher in relation to the discursive rules, selection, sequencing, rhythm and evaluation criteria. There was a variation in control intensity, when teachers and students shared the resolution of the mathematical task. In addition, the teacher provided open communication and greater engagement to students during the teaching and learning processes.

Keywords: Messages, text, educative curriculum materials.

\section{MENSAJES DE PRÁCTICA PEDAGÓGICA EN TEXTOS DE MATERIALES CURRICULARES EDUCATIVOS: UN ANÁLISIS DESDE LA DIMENSIÓN INTERACCIONAL}

RESÚMEN: El propósito de este artículo fue identificar y caracterizar las variaciones en el mensaje que se dan en la dimensión interaccional, con respecto a la práctica pedagógica escolar representada en los textos de los materiales curriculares educativos. Utilizamos el método cualitativo y el análisis documental como procedimiento. La teoría de Basil Bernstein fue el marco teórico-metodológico, en particular, utilizamos el concepto de encuadre en el estudio. Los resultados obtenidos indicaron que se nota la explicación de los contenidos de Geometría y Álgebra, en cuanto a qué enseñar y cómo enseñar, el uso reproductivo secuencial de la tarea matemática. También con base en los resultados, identificamos que el mensaje en los textos de los materiales curriculares educativos caracteriza un fuerte control del docente en relación a las reglas discursivas, los criterios de selección, secuenciación, ritmo y evaluación. Hubo variación en la intensidad del control, cuando profesores y alumnos compartieron la resolución de la tarea matemática. Además, el docente brindó a los estudiantes una comunicación abierta y un mayor compromiso durante los procesos de enseñanza y aprendizaje.

Palabras clave: Mensajes, textos, materiales educativos curriculares.

\section{INTRODUÇÃO}

Materiais Curriculares Educativos ( $\mathrm{MCE}^{3}$ têm se tornado um campo emergente, referenciado na literatura internacional como uma possibilidade para apoiar a aprendizagem de professores (BEYER; DAVIS, 2009; REMILLARD; HERBEL-EISENMANN; LLOYD, 2009; REMILLARD; KIM, 2017). Segundo Remillard (2018), os materiais devem "falar com" professores sobre as ideias intrínsecas às tarefas matemáticas e não apenas "guiar" as suas ações. Estes materiais precisam apresentar elementos na sua estrutura que venham a ser educativos para professores (REMILLARD, 2018). Davis, Remillard e Kim (2017) sustentam o argumento de que os MCE devem possibilitar aos docentes a elaboração de novas tarefas matemáticas significativas e favorecer a compreensão dos conceitos e processos matemáticos (CYRINO; OLIVEIRA, 2016).

Os MCE são recursos historicamente utilizados para apoiar a aprendizagem de professores e estudantes, tal qual apontam Remillard e Kim (2017) e Remillard (2018), sendo qualquer material físico ou digital - como, por exemplo, livros didáticos, apostilas ou cadernos de atividades produzidos pelas Secretarias de Educação, Municipais e Estaduais. Esse apoio pode se dar pelos elementos constituintes dos MCE, como: orientações quanto às perguntas dos estudantes, respostas de estudantes comentadas, vídeos de uma aula (NIE et al., 2013; AGUIAR; OLIVEIRA, 2014, 2017).

As pesquisas sobre MCE têm se consolidado como um campo emergente de pesquisa na área de Educação Matemática, já que os estudos deste campo se interessam em refletir sobre o que é ensinado e como é ensinado com os materiais, sendo importante tanto para professores(as) - estes(as) fazem uso de tais materiais na sala de aula - como para pesquisadores da área e avaliadores. Portanto, o presente artigo propõe um trabalho que agrega novos elementos ao quadro atual de pesquisas.

Este artigo visa investigar a mensagem da prática pedagógica representada em textos dos MCE, elaborada pelo Observatório da Educação Matemática (OEM-Bahia), sediado na Universidade

\footnotetext{
${ }^{3}$ Para evitar repetições textuais, por vezes, utilizaremos a sigla MCE.
} 
Federal da Bahia (UFBA), pelo Grupo de Estudos e Pesquisas das Tecnologias da Informação e Comunicação em Educação Matemática (GEPETICEM), da Universidade Federal Rural do Rio de Janeiro (UFRRJ), e pelo Grupo Pesquisa sobre Formação de Professores que Ensinam Matemática (GEPEFOPEM), da Universidade Estadual de Londrina (UEL) ${ }^{4}$.

A análise de materiais curriculares educativos, no caso específico da Educação Matemática, pode trazer importantes reflexões sobre o que e como os conteúdos são abordados nesses materiais: o que se refere aos conteúdos que são objeto dos processos de ensino e de aprendizagem, e o como diz respeito ao modo operacional desses processos (MORAIS; NEVES; FERREIRA, 2019). Assim, no sentido de contribuir para melhor compreensão deste tema, desenvolvemos este estudo que pretende identificar e caracterizar as variações na mensagem que ocorrem na dimensão interacional, no que diz respeito à prática pedagógica representada nos textos dos materiais curriculares educativos produzidos por grupos vinculados a três instituições de Ensino Superior. Para isso, utilizamos alguns conceitos da Teoria de Basil Bernstein, seguindo uma abordagem de natureza interpretativa.

$\mathrm{Na}$ próxima seção, apresentamos uma discussão sobre alguns conceitos da teoria de Bernstein (2000) e utilizados no estudo, que serviu para o delineamento metodológico e a discussão dos dados produzidos, abordados nas seções seguintes. Por fim, na sexta seção, as considerações finais.

\section{MATERIAIS CURRICULARES EDUCATIVOS SOB A PERSPECTIVA BERNSTEINIANA}

A expressão "Materiais Curriculares Educativos" é concebida como um conjunto de textos pedagógicos, disponibilizados com a intenção de apoiar tanto a aprendizagem de professores quanto a aprendizagem de estudantes (DAVIS; JANSSEN; DRIEL, 2017; REMILLARD; KIM, 2017). O termo "educativo" refere-se aos professores como aprendizes e a expressão "aprendizagem do professor", às mudanças nos padrões de participação do(a) professor(a) na prática pedagógica da qual participa. Entendemos padrão de participação como uma regularidade nas participações do sujeito, e a aprendizagem de professores, podendo ocorrer em diferentes contextos, por exemplo, a sala de aula, a comunidade escolar, cursos de formação profissional (VILAS BOAS; BARBOSA, 2016; McNEILL et al., 2017).

Nesta pesquisa, na perspectiva de Bernstein (2000), "texto" é todo ato comunicativo realizado por alguém, incluindo qualquer representação pedagógica, falada, escrita, visual, espacial ou expressa na postura. Bernstein (2000) define "prática pedagógica", de maneira ampla, como a relação que pode ocorrer entre pais e filhos, professores e estudantes, assim como entre médico e paciente, dentre outros, em um determinado contexto social, para a produção e reprodução cultural. Usamos o termo "escolar" para denotar as relações estabelecidas entre professor(a) e estudantes na escola. Assim, neste estudo, compreendemos "prática pedagógica escolar" a partir da relação estabelecida entre professores e estudantes para ensinar e aprender conteúdos (OLIVEIRA, 2010), em particular, no trabalho com os materiais curriculares educativos em sala de aula.

Ao pretender identificar e caracterizar as relações entre os sujeitos expressas nos MCE, partimos do pressuposto de que estes contêm textos capazes de possibilitar uma comunicação com professores, por meio de seus elementos criados para desenvolver um determinado conteúdo matemático (AGUIAR; OLIVEIRA, 2017). Com isso, podem tornar visíveis (BERNSTEIN, 2003) alguns aspectos relativos às relações entre professores e estudantes em sala de aula, configurando-se como um meio de comunicação, por meio de seus textos, de ideias e de práticas pedagógicas em sala de aula.

Ao assumir os MCE como um conjunto de textos pedagógicos, estamos partindo do pressuposto de que representam mais do que coleções estáticas de tarefas matemáticas, planos de aula, produções escritas dos estudantes, orientações teóricas a respeito de estratégias metodológicas e de tópicos específicos de Matemática. Eles são constituídos de saberes profissionais e representam uma possibilidade para apoiar a aprendizagem de professores, por meio da(s) experiência(s) realizada(s) por outro(s) professor(es) (REMILLARD, 2018).

\footnotetext{
${ }^{4}$ Os três coordenadores dos MCE, citados no artigo, autorizaram, por meio do Termo de Consentimento Livre e Esclarecido, a divulgação de informações referentes ao objeto de estudo.
} 
Estudos apontam que os modos como professores usam materiais podem variar (BEHM; LLOYD, 2009; BROW, 2009; REMILLARD, 2018). Brow (2009) apresenta cinco etapas possíveis de ser identificadas quando professores relacionam com MCE: a seleção do material; a interpretação dos materiais, tanto no planejamento quanto durante a implementação; a conciliação do material com os objetivos pretendidos; a acomodação dos interesses, experiências e limitações de estudantes; e, por fim, a modificação, que se refere ao fato de quando o(a) professor(a) modifica as estruturas já existentes ou omite partes que não lhe interessam no material.

As relações que docentes estabelecem com MCE como um campo de investigação em Educação Matemática oportuniza conhecer crenças, concepções, aprendizagens, participações e valores atribuídos por esses profissionais aos diferentes níveis do desenvolvimento curricular (LIMA; JANUÁRIO; PIRES, 2016; CRISOTOMO; JANUÁRIO; LIMA, 2017).

O estudo de Lima (2014) teve como objetivo compreender a relação entre professores e materiais curriculares no ensino de números naturais e sistema de numeração decimal. Os resultados apontam que professores se relacionam com os materiais curriculares nas práticas pedagógicas, ora reproduzindo, ora adaptando, mas raramente criando a partir do que era proposto neles. Já nos estudos de Pacheco (2015), na mesma linha teórica de Lima (2014), o objetivo foi investigar como duas professoras dos anos iniciais da Rede Estadual Paulista relacionaram-se com os materiais curriculares específicos do bloco Espaço e Forma dos Parâmetros Curriculares Nacionais. Os resultados evidenciaram que elas usaram de diferentes modos os materiais curriculares em uma mesma aula reprodução, adaptação e criação -, que eram direcionados pelos conhecimentos e concepções dessas profissionais. Ao que se refere à adaptação e criação, no entanto, nem sempre os objetivos das professoras coincidiam com os propósitos conceitual, didático e metodológico do Material Curricular Educativo.

Nesses dois estudos, ambos utilizaram a expressão Material Curricular (MC). Nesta pesquisa, consideramos os MC e os MCE como sendo ambos educativos, em função da intenção de promover a aprendizagem de professores e, consequentemente, de estudantes. Nos estudos desenvolvidos por Lima (2014) e Pacheco (2015), a ênfase foi na relação que professores estabelecem com MCE. Além disso, apresentaram como características comuns as contribuições de Remillard e Brown e colaboradores, como fundamentação teórica para situar e discutir a relação existente entre professores e materiais, bem como os usos que docentes fazem de materiais curriculares educativos, que podem ser classificados como reprodução, adaptação e improvisação (BROWN, 2002, 2009).

Os estudos de Lima (2014) e Pacheco e Pires (2015) corroboram as ideias de McClain et al. (2009), ao argumentarem que a maneira como professores usam os MCE está relacionada ao modo como consideram os seguintes fatores, por exemplo, discussão/reflexão sobre o tema; conteúdo do programa curricular; estrutura do material curricular; relação entre sujeitos na prática pedagógica e investigação da situação-problema (SILVA; BARBOSA; OLIVEIRA, 2013). Outros fatores também foram identificados na pesquisa de Aguiar e Oliveira (2017) como os aspectos que afetam o cotidiano dos estudantes, questões de conteúdos prescritos e ausência de experiência dos estudantes com atividades investigativas, fatores que contribuem significativamente para o tipo de uso dos materiais curriculares educativos.

A partir dos resultados dos estudos, sustentamos que o MCE, por representar uma relação pedagógica, pode expressar uma mensagem, ou seja, uma expectativa de realização contextual, isto é, o que e como se ensina na prática pedagógica escolar com base nos textos de materiais curriculares educativos. Como textos que são, os MCE também comunicam sobre as práticas pedagógicas escolares a que se referem, possuindo, assim, uma mensagem.

Bernstein (2000) utiliza os conceitos de contexto comunicativo e de código para explicitar a noção de mensagem. Para o autor, o conceito de "contexto comunicativo" refere-se ao ambiente no qual a prática pedagógica escolar acontece. O "código" é um princípio regulador, tacitamente adquirido, no qual seleciona e integra significados relevantes (para um determinado contexto); formas de realização (textos produzidos), e contextos evocadores (sala de aula, curso de formação, oficinas, etc.). Portanto, não se pode ensinar um código a ninguém, pois ele é mais aprendido do que ensinado, é inferido por meio da fala e adquirido da mesma forma que se adquirem os códigos linguísticos e gramaticais. A "mensagem", conforme aponta o autor, é produzida pelo exercício de controle que cada sujeito faz 
durante o processo de comunicação, ou seja, a relação entre quem ensina e quem aprende, comunicando os significados de como se pode falar no contexto educacional.

Para compreender as relações de comunicação que comportam, como mensagem, as relações de poder e de controle na prática pedagógica escolar nos textos dos MCE, recorremos aos conceitos de classificação e enquadramento utilizados por Bernstein (2000).

O princípio de "classificação" traduz as relações de poder, sendo utilizado, segundo Bernstein (2000), para examinar os conteúdos a serem transmitidos, ou seja, aquilo que pode ser dito. Assim, admite-se que a classificação pode variar entre forte e fraca devido à força do isolamento dos conteúdos das relações de comunicação. A classificação define o conteúdo da comunicação dentro de um determinado contexto comunicativo. Quando há uma nítida separação sobre os conteúdos, temos uma classificação forte.

No contexto escolar, pode ser considerado forte quando o(a) professor(a) de determinada disciplina, como a Matemática, não faz relações com o conteúdo de outras disciplinas escolares, por exemplo, como Ciências ou Geografia, ou ele(a) não leva em consideração os conhecimentos prévios dos estudantes e dúvidas que não apresentam relação com o conteúdo abordado em sala de aula. Com isso, o(a) professor(a) não possibilita aos estudantes estabelecerem relações entre os conteúdos estudados em Matemática e outros conhecimentos, tanto escolares como cotidianos. Uma fraca classificação, por sua vez, representa um esbatimento das fronteiras entre conteúdos.

Para Bernstein (2000), o "enquadramento" regula as relações de controle dentro de um contexto - os textos dos MCE em nosso caso, e dita como o conteúdo pode ser transmitido na relação pedagógica, isto é, quando o(a) professor(a) é quem determina o que será ensinado aos estudantes e não permite nenhuma interferência, temos um exemplo de enquadramento forte. Em contrapartida, quando o controle é partilhado na interação professor(a)/estudantes sobre as características distintivas dos princípios interativos e localizacionais que constituem o contexto comunicativo, o enquadramento é fraco. Compreendemos como princípios interativos a comunicação oral, escrita, visual e gestual e, como princípios localizacionais, os sujeitos, os objetos e o espaço físico.

Portanto, consideramos os materiais curriculares educativos como um texto pedagógico, o que significa dizer que comportam alguma mensagem sobre a prática pedagógica escolar neles expressa. No contexto educacional, por exemplo, a produção de um texto em uma aula de Matemática decorre da consideração das regras de reconhecimento (o que pode ser dito) e da utilização das regras de realização (como pode ser dito) (BERNSTEIN, 2000).

Para referir-se ao contexto em que a prática pedagógica escolar acontece, Bernstein (2000) associa o conceito de contexto comunicativo a dois princípios fundamentais: o interacional e o organizacional. O primeiro - que nos interessa nesta pesquisa - perpassa a relação entre professor(a)/estudante, sendo as regras discursivas ligadas ao controle do contexto comunicativo, que consistem na seleção, no sequenciamento, na ritmagem e no critério de avaliação, juntamente com a postura e a posição dos sujeitos envolvidos na prática pedagógica escolar. O segundo princípio regula a localização física e a forma de sua realização, ou seja, a relação mútua e o espaço no qual os sujeitos estão envolvidos. Assim, consideramos o princípio interacional do contexto comunicativo, como uma das dimensões da mensagem, criando as regras específicas para gerar aquilo que conta como comunicação ou conjunto de textos possíveis.

Para analisar a dimensão interacional da prática pedagógica escolar recorremos ao conceito de enquadramento, utilizado conforme Bernstein (2000), o que significa dizer, no contexto educacional, que o enquadramento regula a realização da comunicação entre os sujeitos em interação, isto é, estamos interessados em compreender como as relações de controle entre professores e estudantes, e entre estudantes, são estruturadas e compartilhadas por meio dos textos nos MCE.

Segundo Bernstein (2003), a regra discursiva seleção diz respeito aos princípios que estabelecem a seleção do tema, assuntos, tarefas, materiais utilizados, conteúdos ou, por exemplo, dos dados expressos nos textos dos materiais curriculares educativos. Já a regra discursiva sequenciamento refere-se aos princípios que estabelecem o que vai ser aprendido antes e o que vai ser aprendido depois (FERREIRA; MORES, 2017; MORAIS; NEVES; FERREIRA, 2019). A regra discursiva ritmagem compreende o tempo destinado à aprendizagem (FERREIRA; MORES, 2017; MORAIS; NEVES; FERREIRA, 2019). A regra discursiva critério de avaliação está ligada à instrução, ou seja, ao grau de 
explicitação do(a) professor(a) ao comunicar-se com estudantes durante a exploração do conteúdo (FERREIRA; MORES, 2017; MORAIS; NEVES; FERREIRA, 2019).

Em termos teóricos e metodológicos, nosso estudo aproxima-se dessas investigações apresentadas, mas distancia-se em relação ao lócus empírico. Nosso foco é a mensagem presente em textos de MCE. Após a descrição do quadro teórico, que nos permite dialogar com os dados deste artigo, nosso objetivo é identificar e caracterizar as variações na mensagem que ocorrem na dimensão interacional, no que diz respeito à prática pedagógica escolar representada nos textos dos materiais curriculares educativos. Na próxima seção, apresentamos detalhes sobre o contexto da pesquisa.

\section{PROCEDIMENTOS METODOLÓGICOS}

Em consonância com o objetivo deste estudo, a presente investigação tem natureza qualitativa (LUDKE; ANDRÉ, 2012), pois a intenção foi identificar e caracterizar as relações de controle entre professor(a)/estudante e entre estudantes, as quais são representadas por meio de textos dos MCE, sendo reguladas pelas regras discursivas (seleção, sequência, ritmagem e critérios de avaliação) que caracterizam as variações nas mensagens.

Para isso, utilizamos a análise documental como o procedimento principal de produção dos dados, buscando identificar informações factuais nos mesmos, atendendo sempre às questões de interesse (KRIPKA; SCHELLER; BONOTTO, 2015). Desse modo, procuramos produzir novos conhecimentos a respeito do fenômeno estudado - Materiais Curriculares Educativos -, a partir das perspectivas captadas nos seus documentos, no caso desta pesquisa os documentos analisados foram MCE produzidos pelo grupo GEPETICEM, OEM e GEPEFOPEM.

O primeiro documento refere-se ao material curricular educativo produzido pelos membros do Grupo de Estudos e Pesquisas das Tecnologias da Informação e Comunicação em Educação Matemática (GEPETICEM), da Universidade Federal Rural do Rio de Janeiro (UFRRJ), sob a coordenação do Professor Dr. Marcelo Almeida Bairral. Esse material explora conteúdos de matemática do Ensino Fundamental II e Médio, com uso do ambiente de Geometria Dinâmica com tecnologia digitais. O material encontra-se disponível em um repositório de acesso livre, sendo possível efetuar download em sua totalidade ou em parte dele. Neste caso, analisamos os conteúdos existentes nas abas: apresentação do material, tarefa matemática para o estudante, respostas dos estudantes e narrativa do(a) professor(a). Para a operacionalização de nossa análise, designamos três materiais escolhidos da seguinte forma: MCE1 aborda o tema "Geometrizando sistemas lineares 2x2"; MCE2 trata dos "Pontos notáveis no triângulo" e o material MCE3 é "Construindo e analisando gráficos do Índice de Desenvolvimento Humano".

O segundo documento comporta materiais produzidos pelo grupo colaborativo denominado Observatório de Educação Matemática (OEM), vinculado à Universidade Federal da Bahia (UFBA), sob a coordenação do Professor Dr. Jonei Cerqueira Barbosa. Esse material explora conteúdos de matemática do Ensino Fundamental II, sendo analisados os conteúdos das seguintes abas: planejamento, tarefa do estudante, solução do(a) professor(a), solução de estudantes, narrativa do professor e vídeos da sala de aula. Os quatro materiais analisados foram designados da seguinte forma: MCE4 aborda o tema "Identificando ângulos congruentes e bissetriz de um ângulo no Ensino Fundamental"; MCE5 trabalha o tema "Descobrindo relações métricas no triângulo retângulo"; MCE6 trata do tema "Investigando a soma dos ângulos internos de um polígono utilizando o Geogebra" e o material MCE7 retrata o tema "Só o quadrado é quadrilátero".

O terceiro documento analisado foi o material curricular educativo "Recurso Multimídia na Formação de Professores", Caso Multimídia: Os colares, desenvolvido pelo Grupo de Pesquisa sobre Formação de Professores que Ensinam Matemática (GEPEFOPEM), da Universidade Estadual de Londrina (UEL), sob a coordenação da Professora Dra. Márcia Cristina de Costa Trindade Cyrino. Esse material explora o tópico matemático Álgebra do Ensino Fundamental. Os diferentes elementos que compõem esse caso estão organizados em cinco seções: (i) Introdução do Caso Multimídia; (ii) Antes da aula; (iii) A aula; (iv) Reflexão após a aula; (v) Colocar em prática. Com exceção da primeira, em todas as outras seções são propostas questões com a intenção de promover reflexões dos(as) professores(as) em formação. Na última seção, "Colocar em prática", o(a) professor(a) em formação é convidado a elaborar, 
desenvolver e filmar uma aula na perspectiva do Ensino Exploratório ${ }^{5}$, de modo a problematizá-la posteriormente. Para a nossa análise, designaremos este material como MCE8.

O processo de análise começou com a leitura dos conteúdos dos materiais, aba a aba, tendo em conta o cruzamento de dois elementos: conceituais, baseados no quadro teórico, e trechos recortados do corpus dos dados. Assim, identificamos categorias, a priori, que oferecem elementos para analisarmos as regras discursivas dos textos dos MCE, sendo denominadas: a) A seleção dos conteúdos da prática pedagógica; b) O sequenciamento dos conteúdos da prática pedagógica; c) A ritmagem dos conteúdos da prática pedagógica e; d) O critério de avaliação da prática pedagógica.

Cada uma dessas categorias pressupõe ações específicas na prática pedagógica escolar de professores que ensinam Matemática. Tais categorias foram analisadas e interpretadas à luz da teoria de Bernstein (2000) e da literatura de Materiais Curriculares Educativos.

A análise dos dados foi inspirada na perspectiva analítica de Bernstein (linguagem de descrição interna) e nos materiais empíricos (linguagem de descrição externa). Com base na relação entre os conceitos fornecidos pela teoria e os dados sugeridos pelas análises empíricas dos três materiais formou-se uma relação dinâmica, possibilitando, com mais profundidade, compreender a realidade que pretendemos investigar (BERNSTEIN, 2000; MORAIS; NEVES; FERREIRA, 2019).

A linguagem de descrição interna diz respeito aos conceitos contidos em uma teoria (no nosso caso, a teoria de Basil Bernstein, especialmente o princípio de enquadramento) com o propósito de criar uma linguagem conceitual (modelo teórico). Já a linguagem de descrição externa refere-se aos modelos provenientes da relação entre dados empíricos (nesse caso, textos dos materiais) e a linguagem interna de descrição (BERNSTEIN, 2000). Para análise dos dados, em cada categoria, a priori, selecionamos trechos/diálogos dos materiais que apresentam indícios da variação das mensagens. Por fim, discutimos os resultados à luz da literatura e da teoria.

Para isso, foi utilizado o conceito de enquadramento de Bernstein (2000), bem como sua variação (fortalecido ou enfraquecido) que, teoricamente, reflete o controle na relação de comunicação entre professor(a)/estudantes e entre estudantes, ou seja, o grau de intervenção/participação de estudantes nos processos de ensino e de aprendizagem. Em seguida, apresentamos a análise dos dados.

\section{APRESENTAÇÃO E DISCUSSÃO DOS DADOS}

Nesta seção, apresentamos as regras discursivas que foram analisadas individualmente (seleção, sequência, ritmagem e critérios de avaliação). Para isso, utilizamos o conceito de enquadramento e suas variações, na identificação e caracterização das mensagens da prática pedagógica sobre a dimensão interacional (BERNSTEIN, 2000; FERREIRA; MORES, 2017; MORAIS; NEVES; FERREIRA, 2019).

\section{a) A seleção dos conteúdos da prática pedagógica}

Nesta categoria, caracterizamos as mensagens expressas em textos de materiais curriculares educativos quanto à regra discursiva seleção, isto é, quem controla a seleção dos seguintes indicadores: o tema da tarefa, as informações quantitativas, os conteúdos, os recursos utilizados, os procedimentos e as estratégias de resolução.

Os textos dos materiais estão estruturado em tarefas diversas. A tarefa do MCE4, por exemplo, aborda o conteúdo de ângulos congruentes e bissetriz de um ângulo (Figura 1). Na tarefa da Figura 1, o que envolve o conteúdo matemático Geometria e o como o modo de apresentação aos estudantes da tarefa para a resolução. Esta tarefa apresenta-se estruturada, não havendo possibilidade de seleção de outros aspectos além dos previstos aos estudantes. Assim, comunica uma relação professor(a) e estudantes em que o enquadramento é fortalecido, isto é, os materiais representam uma prática pedagógica escolar caracterizada por um controle claro na seleção dos conteúdos, do tema da tarefa, das informações quantitativas e recursos utilizados.

Figura 1 - Tarefa matemática do MCE4

\footnotetext{
${ }^{5} \mathrm{O}$ ensino exploratório é uma perspectiva de aula que assume característica interativa, de constante comunicação entre estudantes e professores (OLIVEIRA; MENEZES; CANAVARRO, 2013).
} 
Caro (a) estudante, a tarefa que vamos realizar envolve congruência de ângulos e bissetriz.

Vamos começar?

1) Construa dois ângulos no software GeoGebra. No primeiro ângulo, trace uma semirreta qualquer a partir do seu vértice. No segundo ângulo, também a partir do vértice do ângulo, trace uma "bissetriz".

a) Comente sobre o que você observou a partir dos procedimentos realizados.

b) $\mathrm{O}$ que podemos concluir em relação à semirreta traçada no primeiro ângulo e à bissetriz traçada no segundo ângulo?

Fonte: www.educacaomatematica.ufba.br

Com base nos oitos materiais que analisamos dos três MCE, na seleção dos conteúdos da prática pedagógica a serem transmitidos, no momento de exploração/discussão da tarefa matemática em estudo, não identificamos qualquer interferência por parte dos estudantes, ou seja, o controle em relação a esta regra discursiva recai totalmente sobre o(a) professor(a), trazemos algumas ilustrações dessa regra discursiva, por exemplo, trechos ilustrativos presentes nos textos dos MCE que evidenciam o controle do(a) professor(a) durante a exploração/discussão e orientação da resolução da tarefa matemática:

Após falarmos da atividade e o objetivo de estarmos realizando-a com a classe, distribuímos as folhas com a tarefa para os estudantes e informamos que poderiam fazê-la em grupo (Narrativa do professor(a) do MCE1);

Eles leram a atividade na aba do quadro branco e em seguida foram para a aba que continha o GeoGebra e começaram a movimentar o triângulo que já estava construído com os pontos notáveis (Narrativa do professor(a) do MCE2);

Distribuí entre os grupos as tarefas e em seguida os kits. Nesses kits, havia dois pares de triângulos, sendo um par azul e um par vermelho (Narrativa do(a) professor(a) do MCE5);

$\mathrm{Na}$ implementação da tarefa, foram entregues a régua, o transferidor e o kit de quadriláteros (um quadrado, um retângulo, um losango, um paralelogramo e dois trapézios: um isósceles e um retângulo). Em seguida, sugeri que os estudantes manipulassem o material que receberam (Narrativa do(a) professor(a) do MCE7);

Pessoal, então nós vamos trabalhar hoje uma tarefa, igual a que a gente fez ontem, então, nós vamos reunir em grupos, novamente, de três pessoas. Presta atenção, nós temos uma tarefa em que a gente tem que seguir em equipe. Tarefa 'Os colares' é o título da tarefa. Todo mundo acompanhando. (Extraído da aba A aula - proposição e apresentação da tarefa - Episódio 1 do MCE8).

Esses trechos dos textos evidenciam uma relação professor(a) e estudantes na qual o controle recai totalmente para $\mathrm{o}(\mathrm{a})$ professor(a) a distribuição da tarefa matemática, bem como a forma como seria desenvolvida, pois era ele(a) quem selecionava, direcionava e indicava todos os momentos da aula. No planejamento da aula, ficou claro o que seria feito naquele momento da realização da tarefa e como seria cada etapa. Os materiais expressam uma relação, por meio de sua estrutura, na qual o controle sobre as regras de seleção não é compartilhado com os estudantes, caracterizando um enquadramento fortalecido, com controle claramente localizado no(a) professor(a).

O estudo de Silva (2012) analisou as tarefas sobre o tema Ambiente em um livro didático de Biologia. Os resultados revelaram que o livro indicava os elementos que constituem as tarefas. Ao reproduzi-las em sala de aula, o(a) professor(a) passa a deter tal controle, cabendo ao estudante apenas resolvê-las. Com isso, a tarefa sobre o tema Ambiente apresentava um grau de enquadramento fortalecido com o controle da seleção, indicado pelo livro e pelo(a) professor(a).

Em consonância com a teoria de Bernstein (2000), Prado, Oliveira e Barbosa (2014) investigaram a imagem da prática pedagógica no ambiente de modelagem matemática representada em materiais curriculares educativos produzidos por um grupo colaborativo. Seus resultados apontaram para a regra discursiva seleção, na qual o(a) professor(a) indicava o tema e o problema, assim como um conjunto de informações quantitativas e qualitativas. Os(As) estudantes determinaram a estrutura, seus próprios procedimentos e soluções, isto é, selecionaram conteúdos matemáticos e informações sobre o tema dentro dos conteúdos e informações pré-selecionados pelo(a) professor(a). 
O estudo de Diniz (2017) analisou materiais curriculares com características educativas. Os resultados apontaram que no controle sobre as regras de seleção das estratégias de resolução das tarefas, dependendo do material, o enquadramento é variável, ora tendendo para forte (quando as estratégias são sugeridas pelo(a) professor(a)), ora tendendo para fraco (quando as estratégias são apresentadas pelos estudantes).

Ao analisar os resultados destas pesquisas, observamos que os textos expressam relações entre professores e estudantes nas quais o enquadramento é fortalecido, isto é, o controle da seleção, na maioria, está centrado no(a) professor(a). Portanto, ele(a) seleciona o "que" deve ser estudado e discutido em sala de aula, limitando a participação do estudante nessa relação. Segundo Morais, Neves e Ferreira (2019), uma característica favorável à aprendizagem dos estudantes da regra discursiva seleção seria um enquadramento fortalecido ao nível macro e enfraquecido ao nível micro, ou seja, aos estudantes deve ser possibilitado algum controle, como, por exemplo, a valorização de suas vivências em comunidade e a integração com os conteúdos escolares, elevando o posicionamento de estudantes, o que se constitui como uma condição para a aprendizagem escolar (PICCOLI, 2009).

Portanto, à luz da teoria de Bernstein (2000), a mensagem sugerida em textos de materiais curriculares educativos, quanto à regra discursiva seleção, expressa um enquadramento fortalecido, pois o(a) professor(a) exerce o controle na seleção e na organização dos conteúdos realizados na comunicação pedagógica, bem como propõe uma organização para o desenvolvimento das aulas, isto é, direciona e indica todos os momentos da aula. Assim, o(a) professor(a) planejou o que dizer e como dizer, elaborando e selecionando as tarefas matemáticas que os estudantes desenvolveriam nas aulas. Esse enquadramento se modificava quando o(a) professor(a) realizava a resolução das tarefas com estudantes.

\section{b) O sequenciamento dos conteúdos da prática pedagógica}

Nesta categoria, o foco de análise incidiu sobre como os textos expressam relações entre professor(a) e estudantes quanto ao controle exercido pelos sujeitos na regra discursiva sequência, isto é, a ordem das ações/conteúdos/estratégias realizadas na comunicação pedagógica.

De forma geral, os textos dos oito MCE apresentaram enquadramento fortalecido, por exemplo, quando determinavam como seria explorada a tarefa matemática, definindo uma ordem na explicação do conteúdo. Nos momentos de sistematização dos aspectos mais relevantes abordados em aula, estes também eram determinados pelo(a) professor(a). Porém, ele (a) permitia intervenções dos estudantes com perguntas durante as explicações, ocasionando a interrupção da sequência que estava a seguir, respondendo às questões levantadas por eles, mesmo que isso implicasse afastar-se um pouco do conteúdo abordado. Consequentemente, tal prática fez com que esse enquadramento diminuísse, mas, normalmente, em seguida, ele(a) retomava a sequência da explicação. Os recortes abaixo exemplificam essa regra discursiva:

$\mathrm{Na}$ tarefa foi pedido aos alunos que criassem três controles deslizantes e plotassem a reta em função dos controles, pois quando movimentassem esta ferramenta a reta gerada iria se movimentar. Depois, foi pedido para colocar a equação $2 x+5 x=3$ e por fim fazer três observações sobre as retas quando as movimentasse (Narrativa do(a) professor(a) do MCE1).

Para a resolução da tarefa a turma foi dividida em grupos de três alunos e foram utilizadas 3 aulas de 50 minutos - duas para implementação e uma para a socialização das ideias desenvolvidas na implementação. Iniciamos a aula fazendo uma leitura coletiva (vídeo 1) e solicitando aos alunos que abrissem o GeoGebra, software apresentado anteriormente à turma, em seguida fizemos a leitura da tarefa que era composta de duas questões. A primeira, solicitava que os alunos construíssem no GeoGebra polígonos de 3, 4, 5 e 6 lados e em seguida desenhassem triângulos internos aos polígonos. Posteriormente deveriam preencher uma tabela que solicitava o número de triângulos formados a partir dos polígonos e a soma dos ângulos internos desse polígono. Já a segunda questão solicitava a soma dos ângulos dos polígonos de 9, 10 e 50 lados (Narrativa do(a) professor(a) do MCE6).

$\mathrm{Na}$ implementação da tarefa, a turma foi dividida em grupos e, logo em seguida, foram entregues a régua, o transferidor e o kit de quadriláteros. Em seguida, sugeri que os alunos manipulassem o material que receberam. Logo após a manipulação e o 
reconhecimento das peças do kit, iniciei as primeiras provocações buscando sondar quais compreensões os alunos tinham sobre os quadriláteros que estavam à disposição (Narrativa do(a) professor(a) do MCE7).

Esses três recortes mostram que o sequenciamento dos conteúdos da prática pedagógica é definido segundo uma ordem apresentada pelo(a) professor(a). Assim, mesmo que haja intervenções dos estudantes, a ordem dos conteúdos foi exclusivamente controlada pelo(a) professor(a) (MORAIS; NEVES; FERREIRA, 2019). Além disso, a análise sugere a existência de uma divisão em etapas para a realização das exigências solicitadas aos estudantes, durante a prática pedagógica escolar, expressa em textos dos materiais. Para melhor compreensão do que estamos expondo, apresentamos trechos de alguns dos materiais e os respectivos sequenciamentos (explícitos), como pode ser dito:

(Trecho 1) Construa dois ângulos no software GeoGebra. No primeiro ângulo, trace uma semirreta qualquer a partir do seu vértice. No segundo ângulo, também a partir do vértice do ângulo, trace uma "bissetriz". a) Comente sobre o que você observou a partir dos procedimentos realizados. b) $\mathrm{O}$ que podemos concluir em relação à semirreta traçada no primeiro ângulo e à bissetriz traçada no segundo ângulo? [Tarefa retirada do MCE4].

(Trecho 2) Observe os triângulos que você recebeu e responda às seguintes questões: a) O que há em comum entre eles? b) Nos dois triângulos sem identificação nos lados, considere a hipotenusa como a base e trace a altura do triângulo em relação à base. Em seguida, corte os dois triângulos no segmento de reta que você traçou. $\mathrm{O}$ que você obteve? c) Nomeie os lados das figuras que você obteve quando cortou os triângulos. Observe e compare com os dois triângulos que têm identificação e registre suas observações [Tarefa retirada do MCE5].

Nos trechos (1) e (2), são apresentadas questões mais gerais da tarefa matemática de Geometria (o que). Por exemplo, no trecho (1), podemos observar que a tarefa solicita ao estudante a construção de dois ângulos com ajuda do GeoGebra, seguida de duas questões auxiliares. A tarefa matemática explicita claramente o conteúdo e o procedimento a serem abordados, no qual professores(as) e estudantes exploram conceitos de Geometria na tarefa matemática (o como). Assim, inferimos que está explícita uma ordem progressiva de desenvolvimento do conteúdo, ou seja, as situações-problema requerem o uso de conteúdo matemático em uma sequência definida, podendo variar de um menor para um maior grau de dificuldade.

No segundo exemplo, trecho (2), a tarefa do material sugere que seja apresentada pelo(a) professor(a) e solicitado aos estudantes que observem os triângulos e respondam as questões auxiliares. Neste caso, podemos inferir que as questões auxiliares expressam, de maneira clara, uma ordem progressiva de estratégias que poderiam ser utilizadas pelos estudantes, limitando, assim, que os estudantes escolham outras estratégias. Isso significa que o texto do material indica um sequenciamento no enunciado da tarefa matemática, o qual, na implementação em sala de aula, segue a estrutura apresentada na mesma.

Portanto, nos dois trechos presentes nos textos dos materiais, podemos perceber que os materiais determinam os passos a serem seguidos ao relocar as tarefas matemáticas no contexto da sala de aula, no que diz respeito à ordem dos conceitos a serem apresentados e à forma de sua apresentação/estruturação, ou seja, está comunicando regras discursivas de sequência explícita (BERNSTEIN, 2000), já que é possível observar, com clareza, que existe uma ordem nos procedimentos para implementação da tarefa matemática. Para Sullivan et al. (2015), a estrutura de uma tarefa matemática - por exemplo, os trechos (1) e (2) apresentados - pode variar de simples sentenças a sentenças complexas, que incluem uma divisão de perguntas de forma organizada, ou uma relação de questões estruturadas, sequencialmente, a fim de promover a compreensão dos estudantes de um conceito ou conteúdo ou tópico matemático (JESUS; CYRINO; OLIVEIRA, 2018).

Os textos nos materiais não indicam uma abertura para os estudantes escolherem seus sequenciamentos de resolução das tarefas, o que tende a sugerir o fortalecimento do enquadramento quanto ao controle sobre as regras de sequência (por exemplo, os itens "a" das tarefas (1) e (2)). Dessa forma, inferimos que o fato de a tarefa deixar explícito uma sequência para o uso dos conteúdos, 
procedimentos ou estratégias, pressupõe que estudantes podem ter maiores possibilidades sobre a decisão de como resolver as tarefas. Ou seja, possam organizar seus pensamentos, seus próprios modos, suas soluções e sistematizações, possibilitando-lhes que tenham um maior controle sobre o desenvolvimento da tarefa no contexto da sala de aula. Podemos traduzir isso, em termos bernsteinianos, como situação de fortalecimento do enquadramento. De acordo com Sullivan et al. (2015), quando a tarefa matemática permite ser resolvida de diferentes modos, ela tem o potencial de engajar estudantes em uma atividade intelectual que desenvolve sua autonomia e autoconfiança.

$\mathrm{Na}$ prática pedagógica escolar, expressa pelos textos dos materiais, em particular, no que se refere à sequência na implementação das tarefas, podemos observar que existe uma sequência sugerida no enunciado da tarefa matemática ou durante a resolução (DINIZ, 2017). Assim, o formato da tarefa indica que o(a) professor(a) controla o que vem antes e o que vem depois, tanto em termos do conteúdo quanto em termos das estratégias e procedimentos.

A partir da leitura dos conteúdos existentes nas abas dos materiais analisados, não ficam explícitas evidências de tomada de decisões contrárias, por parte dos estudantes, quanto às regras de sequenciamento. Ou seja, os materiais sugerem uma relação na qual o controle sobre a sequência está com o(a) professor(a), assumindo-o nas regras de sequenciamento na prática pedagógica escolar, o que, em termos bernsteinianos, configura um enquadramento fortalecido.

No cerne dessa discussão, Silva (2012) retratou, especificamente, como o tema Ambiente foi abordado no livro didático de Biologia, examinando as relações entre professor(a) e estudantes, discurso científico escolar e discurso cotidiano, espaços de estudantes, da escola e da comunidade tal como representados e enquadrados nos textos e nas tarefas relacionadas ao tema Ambiente. Os resultados mostraram que a regra discursiva sequência, de modo geral, estabeleceu a sequência de procedimentos que os estudantes deveriam seguir para realizá-la, ou seja, eles poderiam ler o texto para depois resolver a questão. Com isso, o controle da sequência recai, principalmente, no(a) professor(a), que, utilizando tais tarefas do livro didático, deverá deixar claras as regras que estudantes podem seguir para a produção do texto.

Os resultados do estudo de Prado, Oliveira e Barbosa (2014) mostraram que o(a) professor(a) exerceu um forte controle sobre a sequência dos procedimentos, das estratégias e dos conteúdos. Em outros momentos, os(as) autores(as) mostraram uma possibilidade de reduzir o controle na tarefa matemática: não explicitar nas tarefas o modo como estudantes organizam suas soluções. Isso os leva a ter maiores possibilidades de decidir a ordem de apresentação de suas soluções.

Essas duas pesquisas aproximam-se do nosso estudo, pois ambas se utilizaram do quadro teórico de Basil Bernstein e seus resultados dialogam com nossos resultados, já que suas análises evidenciaram um sequenciamento sugerido pelo(a) professor(a) no enunciado da tarefa (DINIZ, 2017), tanto no uso do livro didático de Biologia (SILVA, 2012), quanto no conteúdo dos materiais curriculares educativos sobre modelagem matemática (PRADO; OLIVEIRA; BARBOSA, 2014).

Com base nos nossos dados, o(a) professor(a) assumiu maior controle sobre a regra discursiva sequência na prática pedagógica escolar. No entanto, concordamos com Silva (2012) quando argumenta que, em termos de seleção e sequência, a ocorrência majoritária de enquadramentos fortalecidos pode não favorecer a produção de textos pelos estudantes. Neste caso, chama atenção para a variação dos níveis de enquadramento, de modo que aos estudantes seja dada autonomia para apresentar suas estratégias de resolução, não ficando apenas sob o controle do(a) professor(a). Isso significa que ele(a) pode sugerir um sequenciamento no enunciado da tarefa matemática que pode ser alterado tanto pelo(a) professor(a) como pelos estudantes, na implementação em sala de aula (DINIZ, 2017).

Em geral, os trechos dos textos dos materiais permitem-nos caracterizar que a mensagem de enquadramento fortalecido na relação professor(a) e estudantes é expressa na regra discursiva sequenciamento, isto é, a realização das tarefas matemáticas segue uma ordem determinada pelo(a) professor(a), no enunciado da tarefa ou durante a resolução, assumindo o controle sobre as regras de sequenciamento na prática pedagógica escolar. Portanto, professores(as) planejaram o que dizer e como dizer, elaborando e sequenciando as tarefas matemáticas que os estudantes desenvolveriam nas aulas. 


\section{c) A ritmagem dos conteúdos da prática pedagógica}

Nessa categoria, apresentamos mensagens de quem estabelece a relação entre os conteúdos abordados e o tempo realizado na comunicação pedagógica. Ao analisarmos as abas de seis materiais (MCE1, MCE2, MCE3, MCE5, MCE6 e MCE7), observamos que, na realização da tarefa matemática, $\mathrm{o}(\mathrm{a})$ professor(a) não marcou o tempo destinado à sua execução, mas, durante a realização da mesma, a ritmagem dos conteúdos da prática pedagógica vai sendo conduzida pelas perguntas do(a) professor(a) durante a dinâmica na sala de aula.

No entanto, os textos dos MCE4 e MCE8 apresentaram mais elementos para essa regra discursiva. Para isso, extraímos alguns trechos que nos pareceram mais significativos para ilustrar a relação entre professor(a) e estudantes, sobre a regra ritmagem, expressa nos textos desses materiais. Como exemplo, no MCE8, fica evidente que o texto do material sugere o controle do(a) professor(a) sobre o tempo ou a velocidade esperada das regras de sequenciamento, pois marca o tempo destinado à tarefa no início e, ainda, que seja realizada em sala de aula, juntamente, havendo, assim, um controle do tempo escolar, como pode ser visto na fala da professora: "Vamos lá então, hoje vocês vão ter um tempo para fazer a tarefa, quando der o tempo, eu vou avisar a todo mundo. Terminou, silêncio" (A aula proposição e apresentação da tarefa - episódio 1).

Outro trecho do texto do material evidencia como a professora controlava o tempo em sala de aula: "Acho que o tempo poderia ser um pouco maior para eu poder explorar mais aquela última parte ali da sistematização" (Descrição - reflexão após aula - discussão coletiva da tarefa). Também observamos que o texto do material indica a preocupação da professora com o tempo de realização da tarefa, imprimindo, ainda que indiretamente, a velocidade nas discussões e resoluções das questões, como segue: "Então tá, vamos trabalhando que está quase na hora. Maria, vai escrevendo, você vai se perder" (Descrição: A aula - desenvolvimento da tarefa - Episódio 5).

No texto do material MCE4, a professora controla o tempo em sala de aula, ao dizer: "Foi dado um tempo para que realizassem os procedimentos". Em outro momento, argumenta "concedi aos estudantes mais dez minutos para que concluíssem suas respostas". Esses trechos sugerem uma relação em que o(a) professor(a) deixou explícito o tempo destinado à resolução da tarefa. Isto é, mostra o total controle sobre o tempo da realização das tarefas, lembrando aos estudantes o tempo limite e se permitindo o devido prolongamento da realização das tarefas, marcando o ritmo de exploração dos conteúdos, de realização das atividades e do tempo de utilização desses materiais. Tal procedimento denota um fortalecimento na relação professor(a) e estudantes quanto à regra ritmagem na exploração dos conteúdos. Isso significa que não houve uma partilha (relação entre professor(a) e estudantes) do controle sobre o ritmo da prática pedagógica escolar. Neste caso, observamos como a professora controla o tempo na prática pedagógica escolar. Morais et al. (2018) destacam que um enquadramento fortalecido envolve uma ritmagem quase exclusivamente centrada no(a) professor(a), uma vez que envolve a velocidade em que se espera que a aprendizagem ocorra (BERNSTEIN, 2003).

Assim, os textos nos materiais sugerem uma relação em que o(a) professor(a) tem um total controle sobre o tempo de aprendizagem, pois é ele quem dita o ritmo da aprendizagem, ainda que o texto comunique que a tarefa seja realizada de forma conjunta com os estudantes. Nesse sentido, Prado, Oliveira e Barbosa (2014) analisaram as imagens da prática pedagógica nos textos dos materiais curriculares educativos sobre modelagem matemática, apontando, nos resultados, que o controle da imagem de dimensão interacional (relação entre sujeitos) está centrado com maior frequência no(a) professor(a), em detrimento de um controle partilhado entre ele(a) e os estudantes. Sobre o ritmo dessa prática, houve compartilhamento quanto à valorização da fala e ao incentivo aos textos orais produzidos pelos estudantes, bem como foram valorizados os aspectos vindos do cotidiano nos argumentos produzidos pelos estudantes, nas tarefas matemáticas em sala de aula.

Portanto, esses trechos dos textos dos materiais permitem-nos caracterizar que a mensagem expressa em relação à regra discursiva ritmagem reside na valorização do controle sobre o tempo de aprendizagem pertencer ao(à) professor(a). Assim, os textos expressam relações entre professor(a) e estudantes em que o enquadramento é fortalecido. Os materiais sugerem uma relação na qual o(a) professor(a) tende a controlar quantas questões podem ser feitas em uma determinada aula, assim como a duração para cada questão auxiliar e a forma de alguma explicação, o que fortalece o enquadramento quanto ao ritmo com que decorre o processo de ensino e de aprendizagem. 


\section{d) $O$ critério de avaliação da prática pedagógica}

Nessa categoria, apresentamos possíveis indícios do que pode estar explícito ou implícito na apresentação dos conteúdos abordados, tipo de trabalho/atividade realizada na comunicação pedagógica.

A título de exemplo, trouxemos trechos ilustrativos dos textos dos materiais que possam dar indícios dessa mensagem, quando buscamos analisar a relação professor(a)/estudante quanto ao controle dos sujeitos em uma dada relação pedagógica.

Figura 2 - Trecho da transcrição dos diálogos e das ideias das respostas (MCE02)

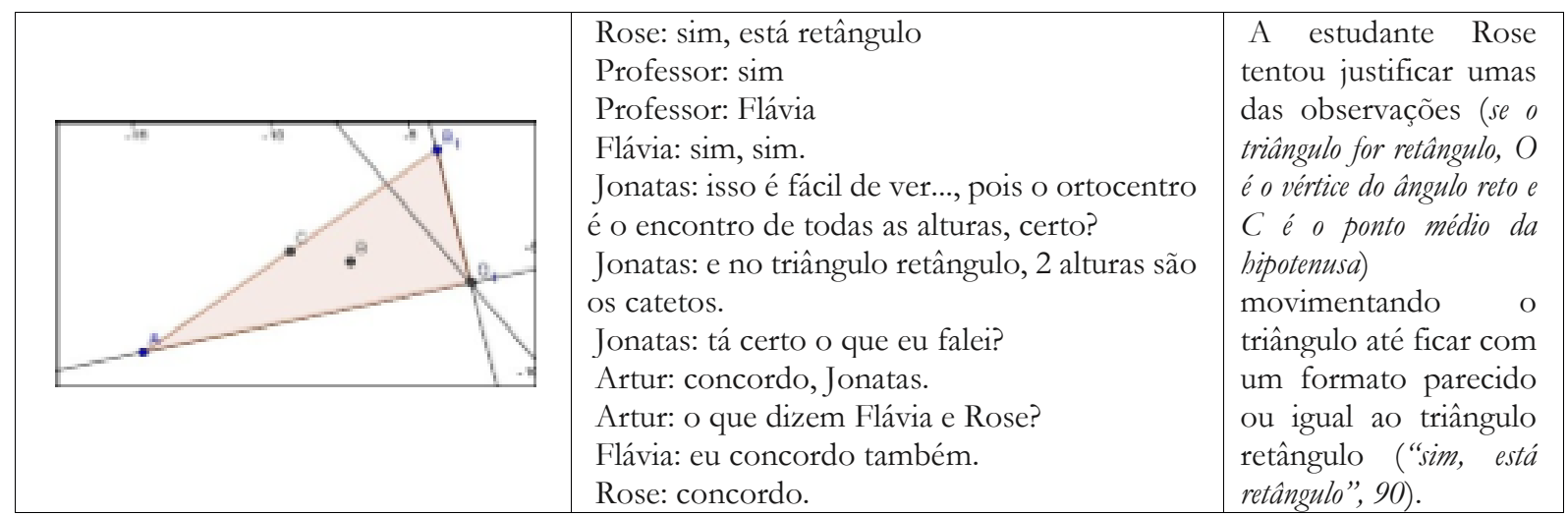

Fonte: www.gepeticem.ufrrj.br

Em termos bernsteinianos, esse trecho presente no material evidencia uma relação na qual professor(a) e estudantes compartilham o controle na resolução da tarefa matemática, conforme apresentado na Figura 2. Os diálogos entre docente e estudantes remetem a uma discussão conjunta na resolução da tarefa matemática. Isso significa dizer que o texto do material sugere a existência de uma comunicação aberta entre os sujeitos (enquadramento enfraquecido), ao possibilitar aos estudantes participarem da discussão, da dinâmica de questioná-los acerca das informações presentes na tarefa matemática, o que pode contribuir para melhor aproveitamento dos estudantes, mesmo que essa comunicação possa configurar uma resposta do(a) professor(a) da forma mais direta, impossibilitando, de certa forma, poucas situações que prolongam o diálogo (SILVA; SOUZA; SANTOS, 2018; MORAIS; NEVES; FERREIRA, 2019). De acordo com Magalhães, Mortimer e Silva (2016), é fundamental para o estabelecimento de diálogos o engajamento de estudantes em situações de diálogo iniciadas pelos questionamentos.

A análise da Figura 2 mostrou que o diálogo na relação entre professor(a) e estudantes foi caracterizado por uma comunicação aberta, em que não só se ouviram várias respostas dos estudantes, durante a resolução da tarefa matemática, como também permitiu inferências, buscando envolver os estudantes na discussão. A regra critérios de avaliação é uma das regras discursivas que não só influenciam, mas também explicam os resultados dos estudantes no primeiro momento, tornando-se ainda mais eficientes quando as relações de comunicação entre os sujeitos são abertas (PIRES; MORAIS; NEVES, 2004; MORAIS; NEVES; FERREIRA, 2019).

Outra característica marcante da prática pedagógica do(a) professor(a), expressa nos textos dos materiais curriculares educativos, diz respeito à definição da tarefa quanto ao seu objetivo, isto é, o(a) professor(a) expressa claramente seus objetivos, deixando sempre evidente para os estudantes o que pretende que façam, pois isso conduz a uma maior possibilidade de êxito quanto à tarefa que é solicitada. O entendimento pelo(a) estudante do que é esperado dele(a) é, muitas vezes, conseguido com o reforço da explicitação por meio da discussão que continuamente ocorre na aula (MORAES; NEVES; FERREIRA, 2019).

A seguir, selecionamos dois trechos para exemplificar a definição da tarefa quanto ao seu objetivo: "Essa tarefa teve como objetivos: reconhecer ângulos internos de um polígono convexo qualquer; calcular a soma dos ângulos internos de um polígono convexo qualquer e generalizar a soma dos seus ângulos internos de um polígono de n lados" (Narrativa do(a) professor(a) do MCE6). O MCE7 apresenta que o "objetivo era identificar quadriláteros a partir de suas propriedades" (Aba planejamento 
do MCE7), enquanto que o MCE4 tinha por objetivo "reconhecer ângulos congruentes como aqueles que possuem a mesma medida" (Aba planejamento do MCE4).

A partir desses trechos, os textos dos materiais curriculares educativos sugerem que o(a) professor(a), ao propor a tarefa matemática, deixou evidente os objetivos da mesma, sempre de forma clara, o que pode gerar compreensão por partes dos estudantes. Isso significa que a regra discursiva critérios de avaliação deve ser explícita e específica para que estudantes reconheçam e saibam o que e como produzir um texto (BERNSTEIN, 2003).

Portanto, o enquadramento para a regra discursiva foi caracterizado como fortalecido, pois inferimos que $\mathrm{o}(\mathrm{a})$ professor(a) deixou claro os objetivos das tarefas matemáticas que os estudantes deveriam realizar e os possíveis procedimentos a serem feitos, naquele momento da aula, de forma clara e direta (GALIAN, 2012). A explicitação da regra discursiva critérios de avaliação, ao contrário do que professores(as) podem argumentar, não impede a criatividade, a autonomia e o desenvolvimento cognitivo dos estudantes, sendo relevante para a aprendizagem dos mesmos.

No trecho a seguir, exemplificamos o compartilhamento do controle na relação entre professor(a) e estudantes: "Atividade 3: atividade de investigação - Procure em algum site de busca informações sobre o IDH da cidade onde você mora e insira na tabela. Compare com os triângulos dos países que você construiu" (Tarefa retirada do MCE3). Neste caso, ao ser proposta a tarefa de investigação, podemos supor que os estudantes tiveram "liberdade" para apresentar suas estratégias ao(à) professor(a), quando solicitados a realizar a atividade extraescolar. É previsto que os mesmos construam diferentes estratégias para melhor abordar o assunto, logo, apresentando diferentes soluções e caracterizando a relação entre professor(a) e estudantes como uma variação no controle, isto é, ele é enfraquecido ao permitir que estudantes participem ativamente da realização da tarefa matemática.

De acordo com os trechos utilizados, houve um enquadramento fortalecido, as explicações dos objetivos da tarefa matemática são detalhadas e claras, porém um enquadramento enfraquecido quando houve o compartilhamento da resolução da tarefa matemática ou quando foi solicitada uma atividade extraescolar para os estudos. Assim, as práticas pedagógicas escolares que variaram os enquadramentos entre fracos e fortes, permitindo-nos caracterizar, em geral, que a mensagem expressa nos textos dos materiais em relação à regra discursiva critérios de avaliação são: professores(as) e estudantes compartilham o controle na resolução da tarefa matemática; a existência de uma comunicação aberta entre os sujeitos; explicitação do objetivo da tarefa matemática e texto a aprender.

\section{CONSIDERAÇÕES FINAIS}

O presente estudo teve a finalidade de identificar e caracterizar a mensagem que ocorre na dimensão interacional e suas variações, no que diz respeito à prática pedagógica escolar representada em textos dos materiais curriculares educativos. Para isso, utilizamos o conceito de enquadramento da teoria de Basil Bernstein para trazer à tona algumas características das mensagens.

A mensagem relacionada com o que se ensina é perceptível na explicitação do conteúdo de Geometria e Álgebra, em textos dos materiais curriculares educativos, sendo apresentados em diferentes representações matemáticas, por exemplo, gráficos, tabelas, figuras geométricas, etc. Cada estudante ou grupo de estudantes foi guiado por sua produção escrita e pelas intervenções escritas/orais do(a) professor(a), podendo seguir um caminho ao lidar com conteúdos contemplados na tarefa matemática (MENDES; BURIASCO, 2018).

Quanto à mensagem relacionada com o como se ensina, os textos dos MCE sugerem o uso sequenciado reprodutivo da tarefa matemática. Aqui, entende-se como seguindo a ordem da tarefa matemática presente no texto do material, organizada sequencialmente e ordenada metodologicamente, controlando o que vem antes e o que vem depois, regulando o ordenamento temporal do conteúdo matemático apresentado aos estudantes.

No uso sequenciado reprodutivo da tarefa matemática, nas regras discursivas, o(a) professor(a) desencadeia ações da prática pedagógica que se constituem como ações pautadas no desenvolvimento da tarefa matemática de ensino. Seu objetivo principal é ajudar estudantes a representar suas resoluções e justificativas, sendo, propriamente, uma relação pedagógica que envolve a relação entre ação de professor(a) e ação de estudantes. Envolve, ainda, algumas ações pedagógicas representadas nos textos dos materiais analisados, tais como: ação de organizar o ambiente em sala de aula; ação de 
apresentar a tarefa matemática; ação de apresentar o objetivo da tarefa matemática; ação de seguir a estrutura do texto; ação do controle do tempo; ação de compartilhar a resolução da tarefa matemática e ação de promover a aprendizagem (ZASLAVSKY, 2017; MATA-PEREIRA; PONTE, 2018).

Sistematizando, as mensagens da dimensão interacional da prática pedagógica escolar são expressas, por meio das regras discursivas, nos textos dos materiais analisados, apresentando uma variação do enquadramento, o que significa que o controle sobre a relação entre sujeitos, por vezes, está centrado no(a) professor(a), em específico nos seguintes aspectos: os conteúdos, o tema da tarefa e as informações quantitativas. Enquanto em outras vezes o controle é compartilhado com estudantes para os seguintes aspectos: os procedimentos e as estratégias de resolução.

A Figura 3, a seguir, representa a relação das ações da prática pedagógica com a tarefa matemática representada em textos dos materiais curriculares educativos analisados.

FIGURA 3 - Ação da prática pedagógica no desenvolvimento da tarefa matemática

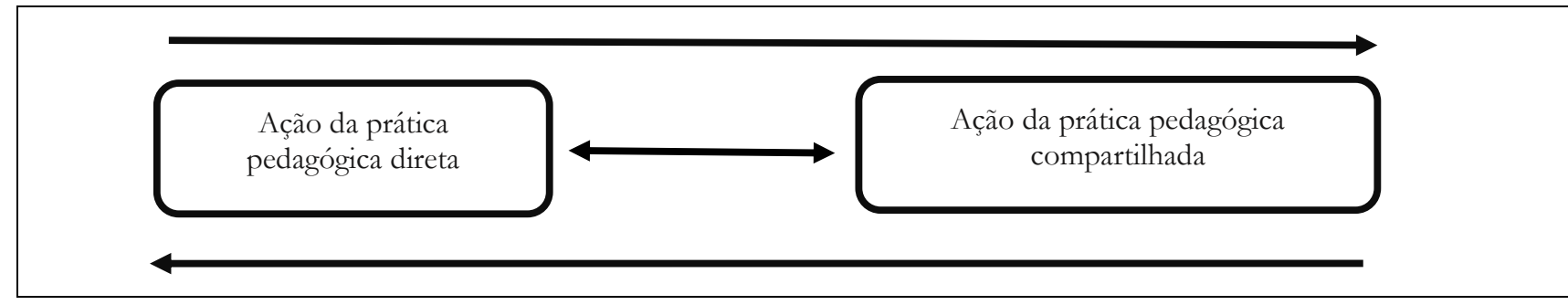

Fonte: Os autores

A partir da análise das regras discursivas apresentadas, caracterizamos a ação da prática pedagógica escolar com a tarefa matemática entre dois extremos: de um lado, a "ação da prática pedagógica direta", a qual caracteriza a ação da prática pedagógica com total controle do(a) professor(a) sobre o uso sequenciado reprodutivo da tarefa matemática, ou seja, uma ação que vai do docente em direção ao estudante, por exemplo, prestam atenção à explicação do(a) professor(a) sobre o conteúdo e a tarefa matemática; recebem auxílio do(a) professor(a) sobre a abordagem do conteúdo e a tarefa matemática; respondem aos questionamentos do(a) professor(a). Do outro, a "ação da prática pedagógica compartilhada", na qual são caracterizadas ações manifestadas pelos estudantes durante a produção de seu texto e/ou ações entre estudantes e professor(a), indicando estratégias de resolução para a tarefa matemática proposta, isto é, uma ação que parte do estudante em direção ao(à) professor(a) e/ou outro estudante na exploração do tema em estudo. Há, assim, o compartilhamento de significados e ideias, uma troca, por exemplo: auxiliam o(a) colega do grupo na resolução da tarefa matemática; discutem e compartilham possíveis estratégias de soluções; recebem auxílio dos estudantes sobre a tarefa matemática, etc.

Desse modo, no decorrer do uso sequenciado reprodutivo da tarefa matemática, ao longo desses processos de ensino e de aprendizagem, podem ser desencadeadas outras ações da prática pedagógica escolar, indo de um extremo ao outro e vice-versa, fazendo surgir uma infinidade de outras ações, caracterizando possíveis comunicações entre esses extremos, a depender dos objetivos da tarefa matemática e das necessidades dos estudantes. Isso caracteriza o movimento entre os extremos de "combinação discursiva", que se referem aos discursos produzidos na relação entre professores e estudantes e entre estudantes no ambiente escolar. Essa abertura na comunicação, entre professores e estudantes e entre estudantes, pode contribuir para melhorar a aprendizagem por parte dos estudantes (FERREIRA; MORES, 2017; MORAIS; NEVES; FERREIRA, 2019). Assim, tal imagem não esgota as possibilidades de ações da prática pedagógica em textos dos Materiais Curriculares Educativos, mas apenas aponta arenas de possíveis aproximações no campo da Educação e Educação Matemática (BARBOSA, 2017).

Portanto, a análise documental que apresentamos neste artigo traz indícios de que os textos dos MCE podem constituir mais um recurso pedagógico de apoio à aprendizagem de professores, pois apresentam um encadeamento sequencial que permite compreender o conteúdo matemático em oportunidades formativas de formação inicial e/ou continuada e a implementação de propostas de formação para professores em exercício. Nesse sentido, a adoção de referenciais teóricos sobre o tema 
pode auxiliar no processo de planejamento e execução de práticas interdisciplinares, na colaboração entre profissionais de diferentes áreas do conhecimento.

Compreender a mensagem dos MCE pode ser um bom ponto de partida para o delineamento de novos Materiais Curriculares Educativos adequados para as práticas pedagógicas de professores que ensinam Matemática. Assim, podendo trazer resultados relevantes para elaboradores dos materiais e/ou para professores que ensinam Matemática, no sentido de informar sobre como está representada a interação entre professores e estudantes na implementação das tarefas matemáticas ali presentes e alertar para certos aspectos inerentes ao desenvolvimento da prática pedagógica. Do mesmo modo, os textos dos MCE trazem contribuições para o campo da Educação e Educação Matemática, especificamente $\mathrm{para} / \mathrm{na}$ formação de professores que ensinam Matemática, pois apresentam sinais no horizonte das práticas e dos conhecimentos que são possíveis dentro de cada material curricular educativo analisado.

Assim, finalizamos este artigo anunciando questões que podem suscitar futuras investigações: Como ocorre a aprendizagem do(a) professor(a) que ensina Matemática a partir do uso dos elementos que constituem os Materiais Curriculares Educativos? Quais são as características das práticas pedagógicas construídas pelo(a) professor(a) que ensina Matemática ao fazer uso das tarefas matemáticas presentes nos Materiais Curriculares Educativos?

\section{Agradecimentos}

Agradecemos aos professores doutores Edvaldo Souza Couto, Jonei Cerqueira Barbosa e Marcelo Almeida Barral e à professora Doutora Márcia Cristina de Costa Trindade. Aos membros do Grupo Ensino de Ciências e Matemática (ENCIMA): Airam Silva Prado, Jamerson dos Santos Pereira, Lilian Aragão da Silva, Patrícia Petitinga Silva, Neomar Lacerda da Silva e Roberta Gondim Britto pelas considerações preliminares à versão prévia deste artigo; e à Pró-Reitoria de Pós-Graduação, Pesquisa e Inovação Tecnológica (PROPIT) da Universidade Federal do Sul e Sudeste do Pará (UNIFESSPA) pelo apoio à pesquisa.

\section{REFERÊNCIAS}

AGUIAR, W. R.; OLIVEIRA, A. M. Uma análise sociológica bernsteniana sobre os usos de materiais curriculares educativos. Educação Matemática Pesquisa, São Paulo, v.19, n.1, p. 403-422, 2017.

AGUIAR, W. R.; OLIVEIRA, A. M. P. A Transformação dos textos dos materiais curriculares educativos por professores de matemática: uma análise dos princípios presentes na prática pedagógica. Boletim de Educação Matemática, v. 28, n. 49, p. 580-600, 2014.

BARBOSA, J. C. Abordagens teóricas e metodológicas na educação matemática: aproximações e distanciamentos. 38 Reunião Nacional da ANPEd - UFMA - São Luís/MA, 2017.

BEHM, S. L.; LLOYD, G. M. Factors influencing student teachers' use of mathematics curriculum materials. In: REMILLARD, J. T.; HERBEL-EISENMANN, B.A.; LLOYD, G. M. (Ed.). Mathematics teachers at work: connecting curriculum materials and classroom instruction. New York: Routledge, 2009. p. 205-222.

BERNSTEIN, B. Pedagogy, symbolic control and identity: theory, research, critique. New York: Rowman \& Littlefield, 2000.

BERNSTEIN, B. Class, codes and control: the structuring of pedagogic discourse. London: Routledge, 2003. v.4.

BEYER, C.; DAVIS, E. A. Supporting preservice elementary teachers' critique and adaptation of science lesson plans using educative curriculum materials. Springer Science+Business Media, B.V, 2009. 
BROWN, M. W. Teaching by design: understanding the intersection between teacher practice and the design of curricular innovations. 543f. Dissertation (Doctor of Philosophy - Field of Education and Social Policy: Learning Sciences). Northwestern University, Illinois/United States, 2002.

BROWN, M. W. The teacher - tool relationship theorizing the design and use of curriculum materials. In: REMILLARD, J. T.; HERBEL-EISENMANN, B.A.; LLOYD, G. M. (Ed.). Mathematics teachers at work connecting curriculum materials and classroom instruction. Routledge, Taylor and Francis: Madison Ave, New York, 2009. p. 38-57.

CYRINO, M. C. C. T.; OLIVEIRA, H. M. Ensino exploratório e os casos multimídia na formação de professores que ensinam matemática. In: CYRINO, M. C. C. T. (Org). Recurso multimídia para a formação de professores que ensinam matemática: elaboração e perspectivas. Londrina: EDUEL, 2016. p. 19-32.

DAVIS, E.; JANSEN, F. J. J. M.; DRIEL, J. H. V. Teachers and science curriculum materials: where we are and where we need to go. Esera, Dubai, Out. 2017.

DINIZ, P. Materiais curriculares educativos e professores que ensinam matemática: mensagem, recontextualização e identidade pedagógica. 2017. 138. Tese (Doutorado em Educação) - Faculdade de Educação, Universidade Federal da Bahia, Salvador, 2017.

FERREIRA, S.; MORAES, A. M. Exigência conceptual do trabalho prático: abordagem multidisciplinar de análise do discurso pedagógico na aula de ciências. Revista Práxis Educativa, Ponta Grossa, v. 12, n. 1, p. 25-47, jan./abr. 2017 Disponível em: http://www.revistas2.uepg.br/index.php/praxiseducativa.

GALIAN, C. V. A. A prática pedagógica e a criação de um contexto favorável para a aprendizagem de ciências no ensino fundamental. Revista Ciência \& Educação, v. 18, n. 2, p. 419-433, 2012.

JESUS, C. R.; CYRINO, M. C. C. T.; OLIVEIRA, H. M. Análise de tarefas cognitivamente desafiadoras em um processo de formação de professores de matemática. Educação Matemática Pesquisa, São Paulo, v. 20, n. 2, p. 21-46, 2018.

KRIPKA, R.; SCHELLER, M.; BONOTTO, D. L. Pesquisa documental: considerações sobre conceitos e caraterísticas na pesquisa qualitativa. In: Atas CIAIQ2015, v. 2. Disponível em: < http://proceedings.ciaiq.org/index.php/ciaiq2015/issue/view/4>.

LIMA, S. F. Relações entre professores e materiais curriculares no ensino de números naturais e sistema de numeração decimal. 2014. 217f. Dissertação (Mestrado em Educação Matemática) Faculdade de Ciências Exatas e Tecnologia, Pontifícia Universidade Católica de São Paulo, São Paulo, 2014.

LIMA, K.; JANUARIO, G.; PIRES, C. M. C. Professores e suas relações com materiais que apresentam o currículo de matemática. Educação Matemática Pesquisa, São Paulo, v. 18, n. 2, p. 717-740, maio/ago. 2016.

LUDKE, M.; ANDRÉ, M. Pesquisa em educação: abordagens qualitativas. São Paulo, SP: EPU, 2012.

MAGALHÃES, S. C.; MORTIMER, E. F.; SILVA, A. F. Uma análise da relação entre a abordagem comunicativa e os tipos de perguntas de duas professoras da educação básica nas aulas de termoquímica. In: Encontro Nacional de Ensino de Química, XVIII., Florianópolis, SC. Anais... 2016.

MATA-PEREIRA, J.; PONTE, J. P. Promover o raciocínio matemático dos alunos: uma investigação baseada em design. Bolema, Rio Claro (SP), v. 32, n. 62, p. 781-801, dez. 2018.

MCCLAIN, K.; ZHAO, Q.; VISNOVSKA, J.; BOWEN, E. Understanding the role of the institutional context in the relationship between teachers and text. In: REMILLARD, J. T.; HERBEL-

EISENMANN, B.A.; LLOYD, G. M. (Ed.). Mathematics teachers at work: connecting curriculum materials and classroom instruction. New York: Routledge, 2009, p. 56-69. 
MCNEILL, K. L.; GONZÁLEZ-HOWARD, M.; MARCO-BUJOSA, L.; LOPER, S.; O’DWYER, L. An examination of how teachers' beliefs about scientific argumentation are impacted by multimedia educative curriculum materials (MECMs). Paper to be presented at the annual meeting of the National Association for Research in Science Teaching (NARST), San Antonio, TX, 2017.

MENDES, M. T.; BURIASCO, R. L. C. A utilização da prova em fases como recurso de ensino em aulas de cálculo. Revista Paranaense de Educação Matemática, Campo Mourão, v.7, n.14, p.39-53, jul./dez. 2018.

MORAIS, A. M.; NEVES, I. P.; FERREIRA, S. O currículo nas suas dimensões estrutural e interacional: perspectiva de Basil Bernstein. Práxis Educativa, Ponta Grossa, v. 14, n. 2, maio/ago. 2019. Disponível em: http://www.revistas2.uepg.br/index.php/praxiseducativa.

NIE, B. et al. An investigation of teachers' intentions and reflections about using Standards-based and traditional textbooks in the classroom. ZDM, v. 45, n. 5, p. 699-711, 2013.

OLIVEIRA, A. M. P. Modelagem matemática e as tensões nos discursos dos professores. 2010. 200f. Tese (Doutorado em Ensino, Filosofia e História das Ciências). Instituto de Física/Departamento de Ciências Exatas, Universidade Federal da Bahia e Universidade Estadual de Feira de Santana, Salvador, 2010.

OLIVEIRA, H.; MENEZES, L.; CANAVARRO, A. P. Conceptualizando o ensino exploratório da matemática: contributos da prática de uma professora do $3^{\circ}$ ciclo para a elaboração de um quadro de referência. Quadrante, v. 22, n. 2, p. 29-53, out. 2013.

PACHECO, D. R..; PIRES, C. M. C. . Impactos de materiais curriculares na prática do professor que ensina matemática nos anos iniciais. Revemat: Revista Eletrônica de Educação Matemática, v. 10, p. 227-242, 2015.

PICCOLI, L. Práticas pedagógicas nos processos de alfabetização e de letramento: análises a partir dos campos da sociologia e da linguagem. Tese (Doutorado em Educação) - Faculdade de Educação, UFRGS, Porto Alegre, RS, 2009. Disponível em: http://www.lume.ufrgs.br/bitstream/handle/10183/18400/000692826.pdf?sequence=1.

PIRES, D.; MORAIS, A.; NEVES, I. Desenvolvimento científico nos primeiros anos de escolaridade. Estudo de características sociológicas específicas da prática pedagógica. Revista de Educação, v. 12, n. 2, p. 119-132, 2004. DOI: 10.1002/tea.3660050403

PRADO, A. S.; OLIVEIRA, A. M.; BARBOSA, J. C. Uma análise sobre a imagem da dimensão interacional da prática pedagógica representada em materiais curriculares educativos. Educação Matemática Pesquisa, São Paulo (SP), v. 16, n. 2, p. 505-535, 2014.

REMILLARD, Janine T.; HERBEL-EISENMANN, Beth A.; LLOYD, Gwendolyn Monica (Ed.). Mathematics teachers at work: connecting curriculum materials and classroom instruction. New York: Taylor \& Francis, 2009.

REMILLARD, J. Mapping the relationship between written and enacted curriculum: examining teachers' decision making. In: KAISER, G. et al. (Eds.), Invited Lectures from the 13th International Congress on Mathematical Education, ICME-13 Monographs, p. 481-498, 2018. Disponível em: https://doi.org/10.1007/978-3-319-72170-5_27.

REMILLARD, J.; KIM, Ok-Kyong. Knowledge of curriculum embedded mathematics: exploring a critical domain of teaching. Educational Studies in Mathematics, p. 1-17, mar. 2017.

SILVA, S. N. O tema ambiente em um livro didático de biologia do ensino médio: uma análise à luz da teoria sociológica de Basil Bernstein. 2012. 206f. Tese (Doutorado em Ensino, Filosofia e História da Ciência) - Universidade Federal da Bahia, Universidade Estadual de Feira de Santana, Salvador, 2012. 
SILVA, M. S.; BARBOSA, J. C.; OLIVEIRA, A. M. P. Materiais curriculares educativos sobre modelagem matemática e a recontextualização pedagógica operada por professores iniciantes. Revista Ibero-americana de Educação Matemática, n.34, p.47-67, 2013. ISSN: 1815-0640.

SILVA, P.; MORAIS, A. M.; NEVES, I. P. O currículo de ciências no 1. ${ }^{\circ}$ ciclo do ensino básico: estudo de (des)continuidades na mensagem pedagógica. Revista Portuguesa de Educação, Braga, v. 26, n. 1, p. 179-217, 2013.

SILVA, R. L.; SOUZA, G. M. S.; SANTOS, B. F. Questionamentos em aulas de química: um estudo comparativo da prática pedagógica em diferentes contextos sociais. Revista Brasileira de Pesquisa em Educação em Ciências, v. 18, n. 1, 2018.

SULLIVAN, P.; ASKEW, M.; CHEESEMAN, J.; CLARK, D.; MORNANE, A.; ROCHE, A.; WALKER, N. Supporting teachers in structuring mathematics lessons involving challenging tasks. Journal of Mathematics Teacher Education, v. 18, p.123-140, 2015.

VILAS BOAS, J.; BARBOSA, J. C. Aprendizagem do professor: uma leitura possível. Ciência e Educação, Buaru, v. 22, n. 4, p. 1097-1107, 2016.

ZASLAVSKY, A. Ação pedagógica, ação comunicativa e didática. Conjectura: Filosofia e Educação, v. 22 , n. 1, p. 69-81, jan./abr. 2017.

Submetido: $23 / 04 / 2019$

Aprovado: $13 / 08 / 2019$ 